\title{
In vivo MRI assessment of a novel Gd'"-based contrast agent designed for high magnetic field applications
}

\author{
Paulo Loureiro de Sousa ${ }^{a} \dagger$, João Bruno Livramento ${ }^{b}$, Lothar Helm ${ }^{b}$, \\ André E. Merbach ${ }^{b}$, William Même ${ }^{c}$, Bich-Thuy Doan ${ }^{a}$, ${ }^{\text {, Jean-Claude Beloeil }}{ }^{a}$, \\ Maria I. M. Prata ${ }^{e}$, Ana C. Santos ${ }^{e}$, Carlos F. G. C. Geraldes ${ }^{f}$ and Éva Tóth ${ }^{a, b *}$
}

\begin{abstract}
$\mathbf{G d}_{3} \mathrm{~L}$ is a trinuclear $\mathrm{Gd}^{3+}$ complex of intermediate size, designed for contrast agent applications in high field magnetic resonance imaging $\left(\mathrm{H}_{12} \mathrm{~L}\right.$ is based on a trimethylbenzene core bearing three methylene-diethylenetriamine$N, N, N^{\prime \prime}, N^{\prime \prime}$-tetraacetate moieties). Thanks to its appropriate size, the presence of two inner sphere water molecules and a fast water exchange, $\mathrm{Gd}_{3} \mathrm{~L}$ has remarkable proton relaxivities at high magnetic field $\left(r_{1}=10.2 \mathrm{vs}^{3.0} \mathrm{~mm}^{-1} \mathrm{~s}^{-1}\right.$ for GdDOTA at $9.4 \mathrm{~T}, 37^{\circ} \mathrm{C}$, in $\mathrm{H}_{2} \mathrm{O}$ ). Here we report an in vivo MRI feasibility study, complemented with dynamic $\gamma$ scintigraphic imaging and biodistribution experiments using the ${ }^{153} \mathrm{Sm}$-enriched analog. MRI experiments were performed at $9.4 \mathrm{~T}$ in mice with $\mathrm{Gd}_{3} \mathrm{~L}$ and the commercial contrast agent gadolinium(III)-1,4,7,10tetraazacyclododecane-1,4,7,10-tetraacetate (GdDOTA). $\mathrm{Gd}_{3} \mathrm{~L}$ was well tolerated by the animals at the dose of $8 \mu \mathrm{mol} \mathrm{Gd} \mathrm{kg}{ }^{-1}$ body weight. Dynamic contrast enhanced (DCE) images showed considerably higher signal enhancement in the kidney medulla and cortex after $\mathbf{G d}_{3} \mathrm{~L}$ injection than after GdDOTA injection at an identical dose. The relaxation rates, $\Delta R_{1}$, were calculated from the IR TrueFISP data. During the excretory phase, the $\Delta R_{1}$ for various tissues was similar for $\mathrm{Gd}_{3} \mathrm{~L}$ and GdDOTA, when the latter was injected at a three-fold higher dose (24 vs $8 \mu \mathrm{mol} \mathrm{Gd} \mathrm{kg}{ }^{-1}$ body weight). These results point to an approximately three times higher in vivo relaxivity (per
\end{abstract}

* Correspondence to: Éva Tóth, Centre de Biophysique Moléculaire, CNRS, Rue Charles-Sadron - 45071 Orléans cedex 2, France.

E-mail: eva.jakabtoth@cnrs-orleans.fr

$\dagger$ Present address: NMR Laboratory, AIM and CEA, Institut de Myologie, La Pitié-Salpêtrière University Hospital, Paris, France.

a P. L. de Sousa, B.-T. Doan, J.-C. Beloeil, É. Tóth

Centre de Biophysique Moléculaire, CNRS, rue Charles Sadron, 45071 Orléans, France

b J. B. Livramento, L. Helm, A. E. Merbach, É. Tóth

Laboratoire de Chimie Inorganique et Bioinorganique, Ecole Polytechnique Fédérale de Lausanne, EPFL-BCH; CH-1015 Lausanne, Switzerland

c W. Même

UPRES EA 2633, Laboratoire de Neurobiologie, Université d'Orléans, Orléans, France

d B.-T. Doan

ICSN, CNRS, avenue de la Terrasse, 91198 Gif sur Yvette, cedex, France

e M. I. M. Prata, A. C. Santos

Instituto de Biofísica e Biomatemática, Faculdade de Medicina, Universidade de Coimbra, Portugal

f C. F. G. C. Geraldes

Departamento de Bioquímica, Centro de RMN e Centro de Neurociências e Biologia Celular, Faculdade de Ciências e Tecnologia, Universidade de Coimbra, Coimbra, Portugal

Contract/grant sponsor: Centre National pour la Recherche Scientifique (France).

Contract/grant sponsor: Swiss National Science Foundation.

Contract/grant sponsor: Swiss State Secretariat for Education and Research.

Contract/grant sponsor: Foundation of Science and Technology, Portugal; contract/grant number: POCTI/QUI/47005/2002.

Contract/grant sponsor: FEDER.

Contract/grant sponsor: EC COST Action D38.

Contract/grant sponsor: EMIL programme; contract/grant number: LSCH-2004-503569.

Contract/grant sponsor: Le Studium.

Abbreviations used: bpm, beats per minute; $B W$, body weight; $C A$, contrast agent; $C(t)$, gadolinium concentration time course in tissue or blood; $D C E$, dynamic contrast enhanced; FLASH, fast low angle shot, fast gradient echo MRI method; FOV, field of view; CGd, gadolinium concentration; GdDOTA, gadoterate meglumine, type of MR contrast agent; HSA, human serum albumin; IR, inversion recovery; i.v., intravenous; PK, pharmacokinetic; RARE, rapid acquisition and relaxation enhancement, fast spin echo MRI method; ROI, region of interest; $T 1$, spin-lattice relaxation time in MR; TE, echo time; $T 1$, inversion time; TR, repetition time; IR TrueFISP, inversion recovery TrueFISP imaging. 
Gd) for $\mathrm{Gd}_{3} \mathrm{~L}$ relative to $\mathrm{GdDOTA}$, thus the ratio of the relaxivities of the two compounds determined in vitro is retained under in vivo conditions. They also indicate that the two inner sphere water molecules per $\mathrm{Gd}$ in $\mathrm{Gd}_{3} \mathrm{~L}$ are not substantially replaced by endogenous anions or other donor groups under physiological conditions. $\mathbf{G d}_{3} \mathrm{~L}$ has a pharmacokinetics typical of small, hydrophilic complexes, involving fast renal clearance and no retention in the blood pool. The dynamic $\gamma$ scintigraphic studies and the biodistribution experiments performed in Wistar rats with ${ }^{153} \mathrm{Sm}$-enriched ${ }^{*} \mathrm{Sm}_{3} \mathrm{~L}$ are also indicative of a fast elimination via the kidneys. Copyright (C) 2008 John Wiley \& Sons, Ltd.

Keywords: magnetic resonance imaging; high magnetic field; contrast agents; gadolinium; in vivo; pharmacokinetics; biodistribution; $\gamma$ imaging

\section{INTRODUCTION}

In magnetic resonance imaging, higher field strength is translated to a better sensitivity and greater spatial or temporal resolution, which explains the current tendency to increase the magnetic field in both clinical and experimental settings. While today $1.5 \mathrm{~T}$ remains the predominant field strength in the clinics, the $3 \mathrm{~T}$ magnet continues to gain market share. In experimental animal studies, magnetic fields $\geq 7.0$ T are commonly applied (1). The signal-to-noise ratio correlates in approximately linear fashion with field strength, thus by increasing the field, the time needed to acquire satisfactory images can be substantially reduced. Alternatively, during the same acquisition time, images at higher resolution can be obtained. Functional MRI and MR spectroscopy benefit particularly from high magnetic fields.

Stable poly(amino carboxylate) complexes of $\mathrm{Gd}^{3+}$ are widely used to enhance image contrast in MRI (2-4). In the last two decades, much effort has been devoted to the improvement of the efficacy of these contrast agents, by modifying the microscopic parameters of the $\mathrm{Gd}^{3+}$ chelates via an appropriate ligand design. For instance, the optimization of the rotational motion by applying slowly tumbling macromolecular complexes led to a considerable relaxivity increase in the intermediate field range, as compared with the commercial, small molecular weight agents GdDTPA or GdDOTA. Typically, these macromolecular chelates have a high proton relaxivity peak centred between 20 and $60 \mathrm{MHz}$. Above this frequency, their longitudinal relaxivity strongly vanishes with increasing field, and at high fields very slow rotation is not beneficial any more for relaxivity. Indeed, the Solomon-Bloembergen-Morgan theory of paramagnetic relaxation (5) predicts that at frequencies above $\sim 200 \mathrm{MHz}$ the relaxivity increases with the inverse of the rotational correlation

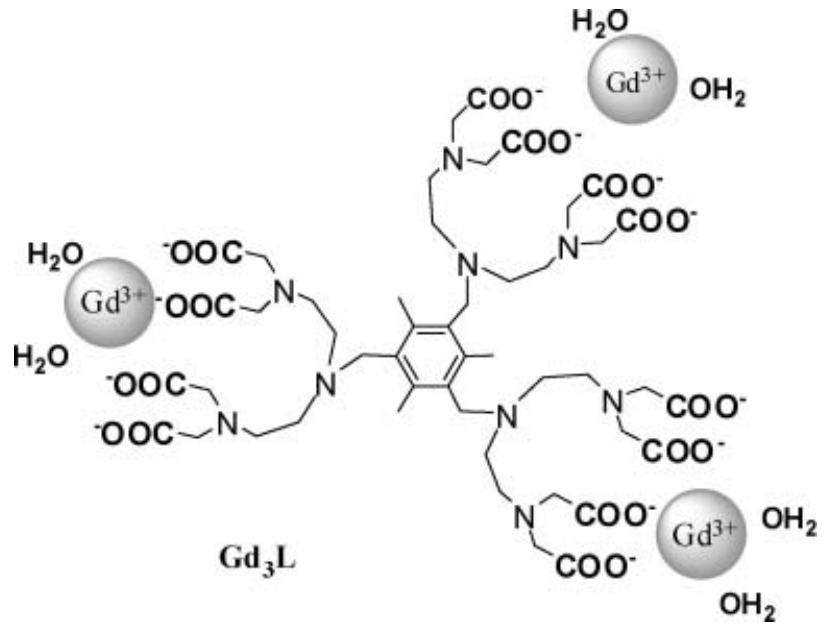

Figure 1. Schematic representation of $\mathrm{Gd}_{3} \mathrm{~L}$. time $\tau_{R}$, in contrast to that at lower frequencies, where it is proportional to $\tau_{\mathrm{R}}$. Consequently, at very high fields intermediate size molecules are favorable over very large ones. Recently we have reported a self-assembled metallostar system with remarkably high in vitro relaxivities at 200 and $400 \mathrm{MHz}(6,7)$. The high efficacy of the metallostar has also been confirmed under in vivo conditions in mice in a comparative MRI study (8). The signal enhancement in the inversion recovery fast low angle shot (IR FLASH) images after the injection of the metallostar at $0.05 \mathrm{mmol} \mathrm{Gd} \mathrm{kg}{ }^{-1}$ body weight (BW) was considerably higher than after GdDOTA injection (at $0.1 \mathrm{mmol} \mathrm{Gd} \mathrm{kg}^{-1} \mathrm{BW}$ ), despite the higher dose of the latter. The metallostar injection resulted in a greater drop in the spin-lattice relaxation time $\left(T_{1}\right)$, as calculated from the inversion recovery TrueFISP imaging (IR TrueFISP) data for various tissues, than the GdDOTA injection. This study also indicated similar pharmacokinetics for the metallostar and for GdDOTA, involving fast renal clearance, a leakage to the extracellular space in the muscle tissue and no leakage to the brain.

One drawback of the metallostar is the limited stability of the $\mathrm{Fe}^{2+}$-tris(bipyridine) core, leading to a slow decomposition in biological conditions which might raise toxicity concerns (7). In order to overcome this problem, a novel chelate, $\mathrm{H}_{12} \mathrm{~L}$, was designed involving covalent linking of three DTTA units to a central xylyl core (DTTA ${ }^{4-}=$ diethylene-triamine-tetraacetate). The ligand $\mathrm{H}_{12} \mathrm{~L}$ forms a trinuclear $\mathrm{Gd}^{3+}$ complex, $\mathrm{Gd}_{3} \mathrm{~L}$, (Fig. 1) which has the appropriate, intermediate size to attain high relaxivities at 4.7-9.4 T. The synthesis of the ligand and the physico-chemical characterization of the $\mathrm{Gd}^{3+}$ complex have been reported elsewhere (9). The in vitro measurements showed that the $\mathrm{Gd}_{3} \mathrm{~L}$ complex indeed has considerably higher $r_{1}$ values at high field as compared with the commercial agents (Table 1). At $400 \mathrm{MHz}$ and $37^{\circ} \mathrm{C}$, its relaxivity is three times superior to that of GdDOTA (10.2 vs $3.0 \mathrm{~mm}^{-1} \mathrm{~s}^{-1}$ ). In addition to the appropriate size of the complex, the presence of two inner sphere water molecules and their efficient exchange rate are also important factors to contribute to this remarkable relaxivity (9).

Table 1. High field relaxivities of selected $\mathrm{Gd}^{3+}$ complexes measured in water $(\mathrm{pH} 7.4)$

\begin{tabular}{|lrrrrrr|} 
& \multicolumn{2}{c}{$200 \mathrm{MHz}(4.7 \mathrm{~T})$} & & \multicolumn{2}{c}{$400 \mathrm{MHz}(9.4 \mathrm{~T})$} \\
\cline { 2 - 3 } \cline { 5 - 6 }$r_{1}\left(\mathrm{mM}^{-1} \mathrm{~s}^{-1}\right)$ & $25^{\circ} \mathrm{C}$ & $37^{\circ} \mathrm{C}$ & & $25^{\circ} \mathrm{C}$ & $37^{\circ} \mathrm{C}$ \\
\hline $\mathrm{Gd}_{3} \mathrm{~L}$ & 17.0 & 14.1 & & 10.7 & 10.2 \\
Metallostar $^{\mathrm{a}}$ & 16.4 & 15.8 & & 9.3 & 8.5 \\
GdDOTA $^{\mathrm{a}}$ & 4.0 & 3.0 & & 3.9 & 3.0 \\
GdDTPA & 4.2 & 3.2 & & 4.1 & 3.1 \\
aLivramento et al. (8). & & & & & \\
\hline
\end{tabular}


Here we report an in vivo MRI feasibility study at 9.4 T using $\mathrm{Gd}_{3} \mathrm{~L}$ as a potential MRI contrast agent dedicated to high magnetic fields. The pharmacokinetics and in vivo relaxivity were assessed in mice and compared with those of a typical commercial, small molecular weight contrast agent, GdDOTA. The MRI results have been complemented with dynamic scintigraphic and biodistribution studies in Wistar rats at short (10-15 min) and long ( $24 \mathrm{~h})$ periods of time by using the ${ }^{153} \mathrm{Sm}$ analog compound, ${ }^{153} \mathrm{Sm}_{3} \mathrm{~L}$.

\section{RESULTS AND DISCUSSION}

\subsection{Magnetic resonance imaging}

Comparative MRI studies have been performed at 9.4 T in mice with $\mathrm{Gd}_{3} \mathrm{~L}$ and GdDOTA. $\mathrm{Gd}_{3} \mathrm{~L}$ was well tolerated by the animals at the dose of $8 \mu \mathrm{mol} \mathrm{Gd} \mathrm{kg}{ }^{-1}$ BW. No gross side effects were observed during the injection, immediately or several days after the experiment. During the experiment, the respiration of the animal was continuously monitored. In the first minute post-injection, a drop in the respiration frequency was detected. The values returned to the pre-injection level after a few minutes. Overall, $\mathrm{Gd}_{3} \mathrm{~L}$ seemed to be harmless to the animals; nevertheless, a more detailed study would be required to further assess its toxicology.

The toxicity of novel $\mathrm{Gd}^{3+}$ complexes to be tested in in vivo experiments is an important concern. The $\mathrm{Gd}^{3+}$ chelate has to be sufficiently stable to avoid any $\mathrm{Gd}^{3+}$ release before total excretion of the contrast agent from the body. This requires sufficient thermodynamic stability and kinetic inertness of the complex (10). Thermodynamic stability was assessed for various GdDTTAtype complexes and showed a limited decrease as compared with GdDTPA. The stability constants determined for the $\mathrm{Gd}^{3+}$ complexes formed with DTTA-derivative chelators were $\log K_{\mathrm{GdL}}=17-19$, with corresponding $\mathrm{pGd}$ values of $\sim 15-16$ $\left([\mathrm{L}]_{\text {total }}=10 \mu \mathrm{m} ;[\mathrm{Gd}]_{\text {total }}=1 \mu \mathrm{m} ; \mathrm{pH} 7.4\right)(7,11)$. These $\mathrm{pGd}$ values are very similar to that of GdDTPA-BMA ( $p G d=15.8)$, one of the clinically approved contrast agents (12). Nevertheless, we are aware that $\mathrm{Gd}_{3} \mathrm{~L}$ is just a model system and cannot be proposed for in vivo human applications. Recently, the lack of high kinetic inertness of certain $\mathrm{Gd}^{3+}$ complexes, in particular GdDTPA-BMA, has been recognized to be associated with the potentially lethal nephrogenic systemic fibrosis/nephrogenic fibrosing dermopathy (NSF/NFD). We have to note, however, that only patients with severe renal failure develop NSF; those who present a very slow excretion of the agent from the body. On the other hand, high-field imaging is primarily used in small animal studies and not for human applications. In small animals the excretion is much more rapid, and therefore the kinetic inertness of the complex is less critical.

\subsection{DCE experiments}

Figure 2 shows a representative series of dynamic contrast enhanced (DCE) images after $\mathrm{Gd}_{3} \mathrm{~L}$ and GdDOTA injections at the same dose of $8 \mu \mathrm{mol} \mathrm{Gd} \mathrm{kg}{ }^{-1}$ BW. In the pre-injection image,

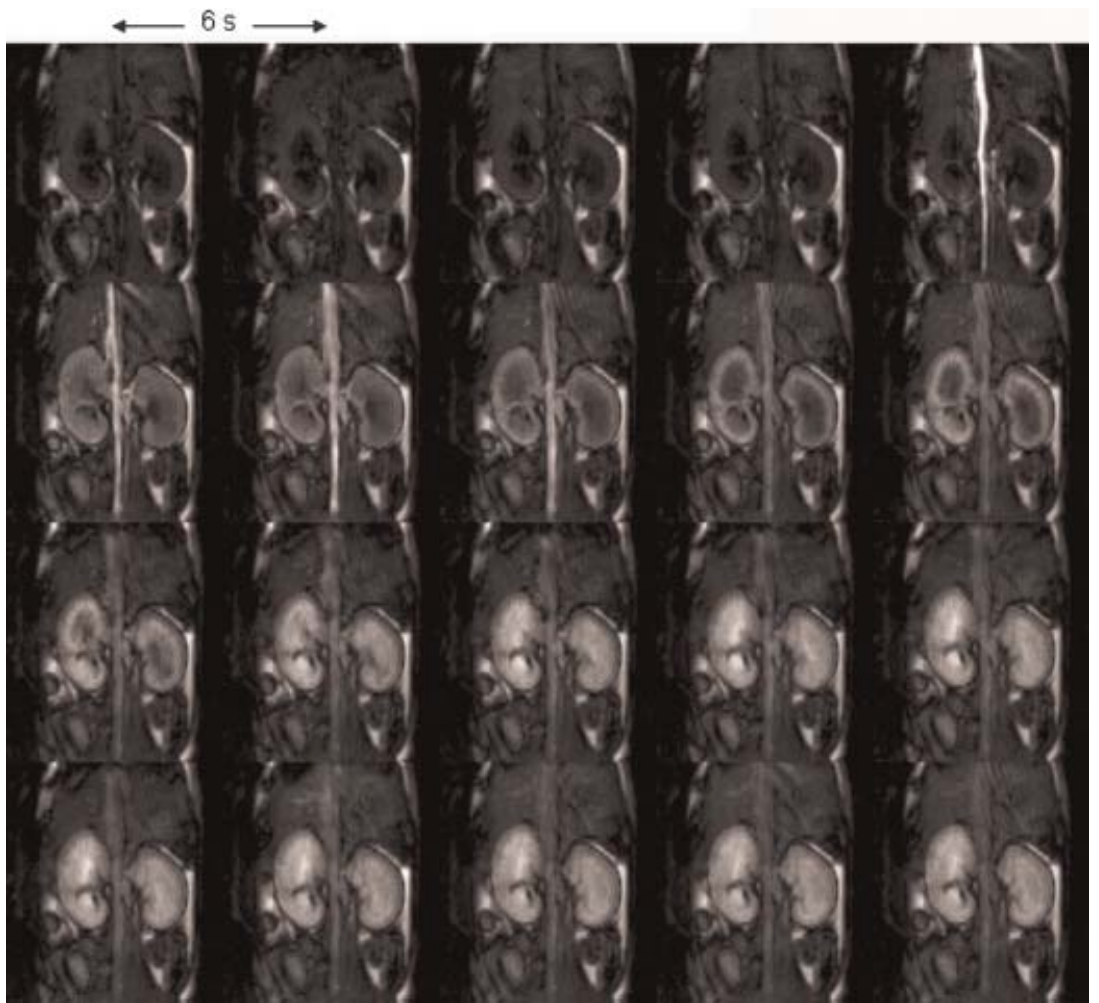

Figure 2. Representative series of dynamic contrast enhanced images after $\mathrm{Gd}_{3} \mathrm{~L}$ injection at a dose of $8 \mu \mathrm{mol} \mathrm{Gd} \mathrm{kg}{ }^{-1} \mathrm{BW}$. In the pre-injection images (first four images), kidney structures (cortex, inner and outer medulla) and adjacent tissues were dark due to the particular inversion delay chosen. A marked change of signal intensity was observed in the vascular system (artery aorta and vein cava) just after bolus injection, followed by a signal enhancement in the renal cortex and later in the medulla. A slight enhancement in the muscle and liver was also observed; $B=9.4 \mathrm{~T}$. 

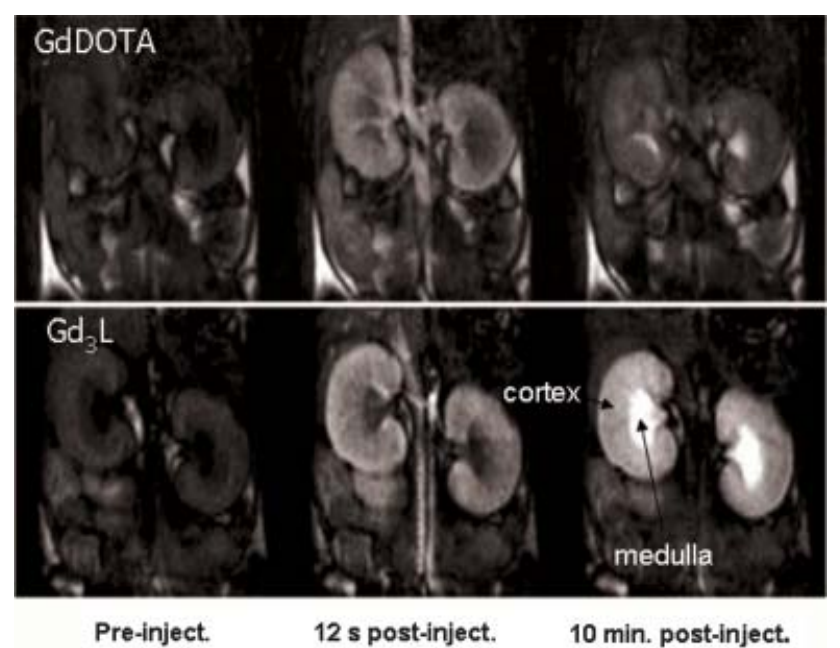

Figure 3. Dynamic contrast enhanced images after GdDOTA and $\mathrm{Gd}_{3} \mathrm{~L}$ injections at the dose of $8 \mu \mathrm{mol} \mathrm{Gd} \mathrm{kg}{ }^{-1}$ BW each. For both agents, marked changes of signal intensity were observed in the vascular system, renal cortex and medulla. At $10 \mathrm{~min}$ post-injection the signal enhancement observed after $\mathrm{Gd}_{3} \mathrm{~L}$ injection is considerably higher as compared with the GdDOTA injection, despite the identical dose of the two agents used; $B=9.4 \mathrm{~T}$.

kidney structures (cortex, inner and outer medulla) and adjacent tissues were dark due to the particular inversion delay chosen.

For both agents, marked changes of signal intensity were observed immediately after bolus injection in the vascular system (artery aorta and vena cava), followed by a signal enhancement in the renal cortex and later in the medulla (Fig. 3). A slight enhancement in the muscle and liver was also observed for both contrast agents (CAs). At $10 \mathrm{~min}$ post-injection, during the renal excretory phase, the signal enhancement observed after $\mathrm{Gd}_{3} \mathrm{~L}$ injection was considerably higher as compared with the GdDOTA injection, despite the identical dose of the two agents used. This finding is in accordance with the remarkably higher relaxivity of $\mathrm{Gd}_{3} \mathrm{~L}$ determined in vitro.

\section{3. $T_{1}$ experiments}

The time course of the relaxation rates $\left(\Delta R_{1}=R_{1}-R_{10}=1 / T_{1}-1\right.$ / $\left.T_{10}\right)$, calculated from the IR TrueFISP data, is shown in Fig. 4 . The increase in the relaxation rate is supposed to be directly proportional to the concentration of the contrast agent delivered to the tissue, if saturation effects are absent. If in vitro CA relaxivities (Table 1) and $\Delta R_{1}$ curves (Fig. 4) are used to estimate the local concentration in the kidney tissues and blood, the $\mathrm{Gd}$ concentration calculated is $\sim 3$ times higher for GdDOTA. This result is consistent with the experimental setup (mice have received a three-fold dose of GdDOTA).

The pharmacokinetics was found to be similar for $\mathrm{Gd}_{3} \mathrm{~L}$ and GdDOTA. Both CAs are primarily eliminated by the kidneys from the blood stream. These finding is in full accordance with previous reports on the pharmacokinetics of the GdDOTA (13-15) or other small molecular weight Gd-based contrast agents (14).

For both CAs, the vascular response was characterized by a sharp maximum $\sim 10 \mathrm{~s}$ after the bolus injection followed by a rapid elimination from the blood. The cortex and medulla
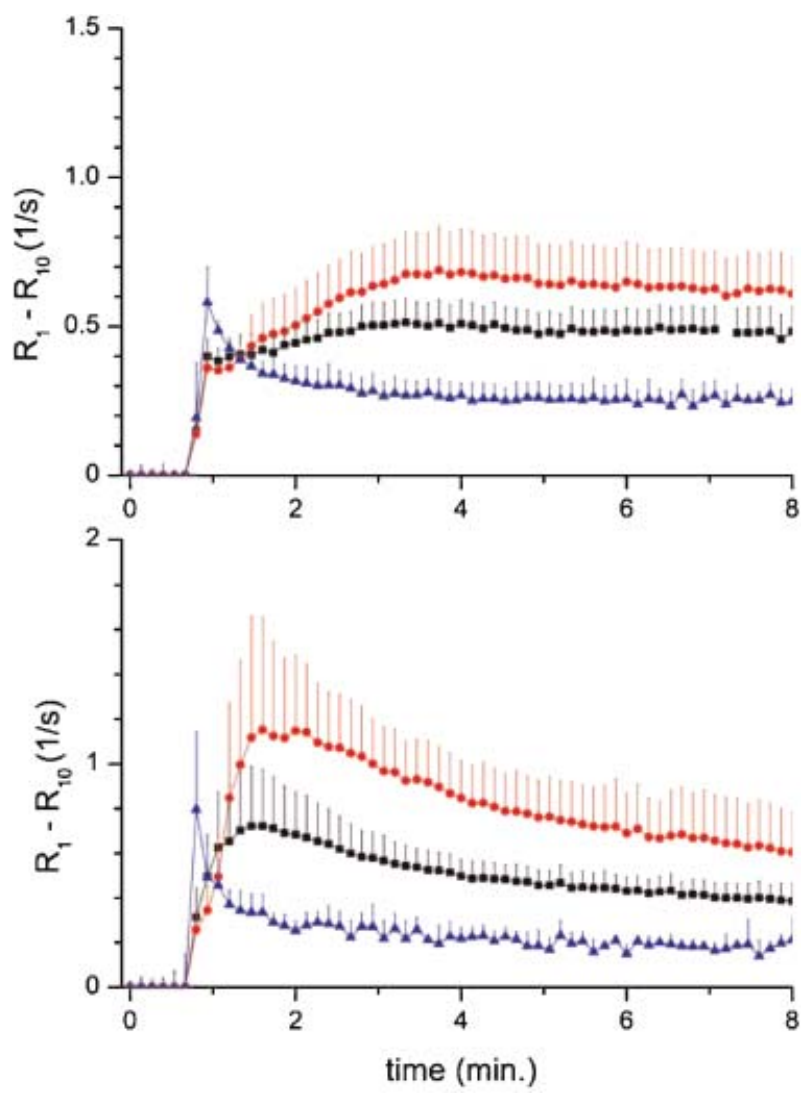

Figure 4. Relaxation rates, $\Delta R_{1}$, calculated from the IR TrueFISP data after GdDOTA (top) and injection $\mathrm{Gd}_{3} \mathrm{~L}$ (bottom) for three different regions of interest: kidney cortex, kidney medulla and the vascular system. During the excretory phase (time $>4 \mathrm{~min}$ ), $\Delta R_{1}$ for renal tissues was similar for $\mathrm{Gd}_{3} \mathrm{~L}$ and GdDOTA when the latter was injected at a dose three times higher $\left(24 \mu \mathrm{mol} \mathrm{Gd} \mathrm{kg}{ }^{-1} \mathrm{BW}\right)$. The time courses represent mean values of $n=6$ animals. Symbols: (solid squares) cortex; (solid circles) medulla; (solid triangles) vascular system (cava); $B=9.4 \mathrm{~T}$.

showed a similar clearance pattern, with a slower rate for medulla. As the elimination rate depends on the dose administered (15), the elimination curves observed for GdDOTA are slightly different from those described in Livramento et al. (8) as a consequence of the lower dose used here. For both CAs, the elimination curve approached a steady-state $\sim 3$ min after injection (a slowly descending segment, corresponding to the predominant excretory function).

For both CAs, the IR-TrueFISP experiment was not sensitive enough to detect $T_{1}$ changes in the muscles and liver (data not shown), probably due to the weak dose used and/or the very short $T_{2}$ found in these tissues.

It has been shown previously that the in vitro and in vivo relaxivities of $\mathrm{Gd}$-based contrast agents can be significantly different, the latter being affected by the tissue structure and physiology $(16,17)$. It has been demonstrated that GdDTPA has considerably lower relaxivities in the rat kidney cortex or medulla than measured in saline solution or in other tissues, which is related to the compartmentalization of the contrast agent in the kidney $(18,19)$. Evidently, the quantitative determination of the in vivo relaxivity of a contrast agent requires knowledge of its local concentration. In some cases, this concentration has been 
obtained by independent measurements. These studies, however, are not without difficulties, since they often induce significant perturbations to the tissues by studying intact excised tissues (20), making measurements post-mortem (18) or ensuring a constant infusion of the contrast agent in order to establish a steady state concentration (19). In the absence of such experiments, only an estimation of the relative in vivo relaxivity can be performed if we assume similar pharmacokinetics for GdDOTA and $\mathrm{Gd}_{3} \mathrm{~L}$. In this case, the relative in vivo relaxivity of $\mathrm{Gd}_{3} \mathrm{~L}$ as compared with that of GdDOTA can be obtained by:

$$
\frac{\left(r_{1}\right)_{\mathrm{Gd}_{3} \mathrm{~L}}}{\left(r_{1}\right)_{\mathrm{GdDOTA}}}=\frac{(\text { dose })_{\mathrm{GdDOTA}}}{(\text { dose })_{\mathrm{Gd}_{3} \mathrm{~L}}} \cdot \frac{\left(\Delta R_{1}\right)_{\mathrm{Gd}_{3} \mathrm{~L}}}{\left(\Delta R_{1}\right)_{\mathrm{GdDOTA}}}
$$

For the sake of simplicity, if CA relaxivities are compared for the period of the excretory phase (a slowly descending segment, starting $\sim 3$ min post-injection, corresponding to the predominant excretory function), $\Delta R_{1}$ for various tissues was similar for $\mathrm{Gd}_{3} \mathrm{~L}$ and GdDOTA, when the latter was injected at a dose three times higher $\left(24 \mu \mathrm{mol} \mathrm{Gd} \mathrm{kg}{ }^{-1}\right.$ BW). Table 2 summarizes the variation of $\Delta R_{1}$ across different regions of the kidney after $\mathrm{Gd}_{3} \mathrm{~L}$ and $\mathrm{GdDOTA}$ injection, during the excretory phase. No significant $(p<0.01)$ differences were found between the $\Delta R_{1}$ values measured for the two different contrast agents, despite the different doses applied. Using the average $\Delta R_{1}$ values given in Table 2 and taking into account the 3 -fold higher dose of GdDOTA, we find that the in vivo $r_{1}$ for $\mathrm{Gd}_{3} \mathrm{~L}$ is approximately three times higher than for GdDOTA.

The renal clearance, based on the observation of the $\Delta R_{1}$ values in the three different regions of interest (kidney cortex, kidney medulla and the vascular system), was similar to that previously reported for the metallostar compound (8) and for other small-molecular-weight Gd-based contrast agents $(13,14)$. As the high $\Delta R_{1}$ values of the kidney medulla show, $\mathrm{Gd}_{3} \mathrm{~L}$ is predominantly eliminated from the blood stream by the kidneys, analogously to GdDOTA or to other small chelates. Furthermore, as expected on the basis of its relatively small size, $\mathrm{Gd}_{3} \mathrm{~L}$ does not function as a blood pool agent.

Clearly, we do not have any evidence on the identical biodistribution of GdDOTA and $\mathrm{Gd}_{3} \mathrm{~L}$. As explained above, the quantitative assessment of the in vivo contrast agent concentration can be only achieved via very invasive methods, which were beyond the scope of this study. In order to proceed in the most cautious way, the comparison of the relaxivity of the two compounds was done in the excretory phase where the experimentally measured relaxation rates attain a very slowly descending segment. In this quasi-stationary phase, different pharmacokinetic behavior has less influence on the comparison. We believe that the fact that the relaxivity ratio calculated is close to what is found in vitro is probably not a coincidence. Also, the

Table 2. Average $\Delta R_{1}$ values $(n=6$, mean $\pm \mathrm{SD})$ in various kidney regions during the excretory phase; $B=9.4 \mathrm{~T}$

\begin{tabular}{|lcc|} 
Region & $\begin{array}{c}\Delta R_{1}\left(\mathrm{~s}^{-1}\right) \\
\mathrm{Gd}_{3} \mathrm{~L}^{\prime}\end{array}$ & $\begin{array}{c}\Delta R_{1}\left(\mathrm{~s}^{-1}\right) \\
\mathrm{GdDOTA}^{-1}\end{array}$ \\
\hline $\begin{array}{l}8 \mathrm{mmol} \mathrm{kg}^{-1} \mathrm{BW} \\
\text { Kidney cortex }\end{array}$ & $0.43 \pm 0.07 \mathrm{~s}^{-1}$ & $0.49 \pm 0.07 \mathrm{~s}^{-1}$ \\
Kidney medulla & $0.71 \pm 0.19 \mathrm{~s}^{-1}$ & $0.64 \pm 0.20 \mathrm{~s}^{-1}$ \\
Aorta/cava & $0.19 \pm 0.05 \mathrm{~s}^{-1}$ & $0.25 \pm 0.05 \mathrm{~s}^{-1}$ \\
\hline
\end{tabular}

time-dependent relaxation rates measured in the blood (Fig. 4, blue curves) seem to indicate that the rate of elimination of the agent from the blood is very similar for the two compounds.

Furthermore, the high relaxation efficiency of $\mathrm{Gd}_{3} \mathrm{~L}$ under in vivo conditions suggests that the two inner sphere water molecules are not (or not substantially) replaced by endogenous anions or other potential donors from proteins, etc., in the biological medium. The same observation was made in the animal imaging experiments previously performed with the metallostar compound, containing an identical DTTA chelator to complex $\mathrm{Gd}^{3+}$. This finding is very important and favors the DTTA chelates in comparison to the macrocyclic bishydrated DO3A-type $\mathrm{Gd}^{3+}$ complexes, which tend to form ternary complexes with a variety of endogenous carboxylate donors (21).

\subsection{Biodistribution and dynamic scintigraphic studies}

In order to gain further insight into the in vivo behaviour of the trinuclear $\mathrm{Gd}_{3} \mathrm{~L}$, we performed biodistribution and dynamic $\gamma$ scintigraphic studies in Wistar rats using the $\mathrm{Sm}^{3+}$ analog complex where the gadolinium was replaced by a mixture of radioactive $\left({ }^{153} \mathrm{Sm}\right)$ and non-radioactive samarium $(22,23)$.

The scintigraphic image obtained $200 \mathrm{~s}$ after tracer injection of $\mathrm{Sm}^{*}{ }_{3} \mathrm{~L}$ is shown in Fig. 5. As this figure shows, and in full accordance with the MRI findings, the main activity is located in the kidneys and the bladder, which represent the typical excretion pathway for such a small and hydrophilic complex. A rapid clearance from all other organs is also observed. The time-activity curves, obtained from the dynamic acquisition experiments, are shown in Fig. 6 . The curves were smoothed and normalized in relation to the maximum activity obtained. The clearance of the compound via the kidneys was confirmed again. The liver-spleen curve was similar to the thorax curve, corresponding only to blood activity.

The characteristics of the renal clearance and washout of $\mathrm{Sm}_{3}^{*} \mathrm{~L}$ were further investigated by biodistribution studies in Wistar rats. The results obtained at $15 \mathrm{~min}$ and $24 \mathrm{~h}$ post-injection

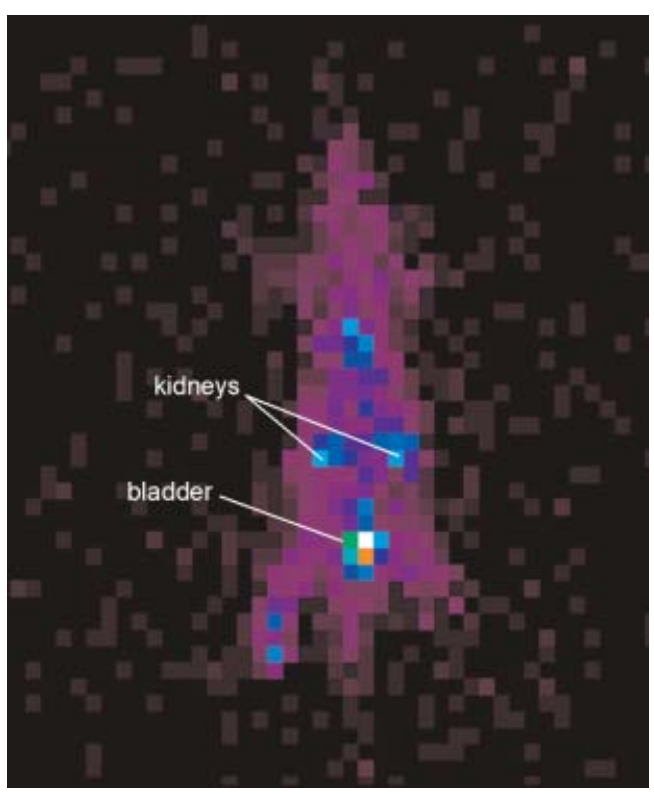

Figure 5. Scintigraphic dynamic image obtained $200 \mathrm{~s}$ after intravenous injection of ${ }^{153} \mathrm{Sm}_{3} \mathrm{~L}$ in a Wistar rat. This figure is available in colour online at www.interscience.wiley.com/journal/cmmi 


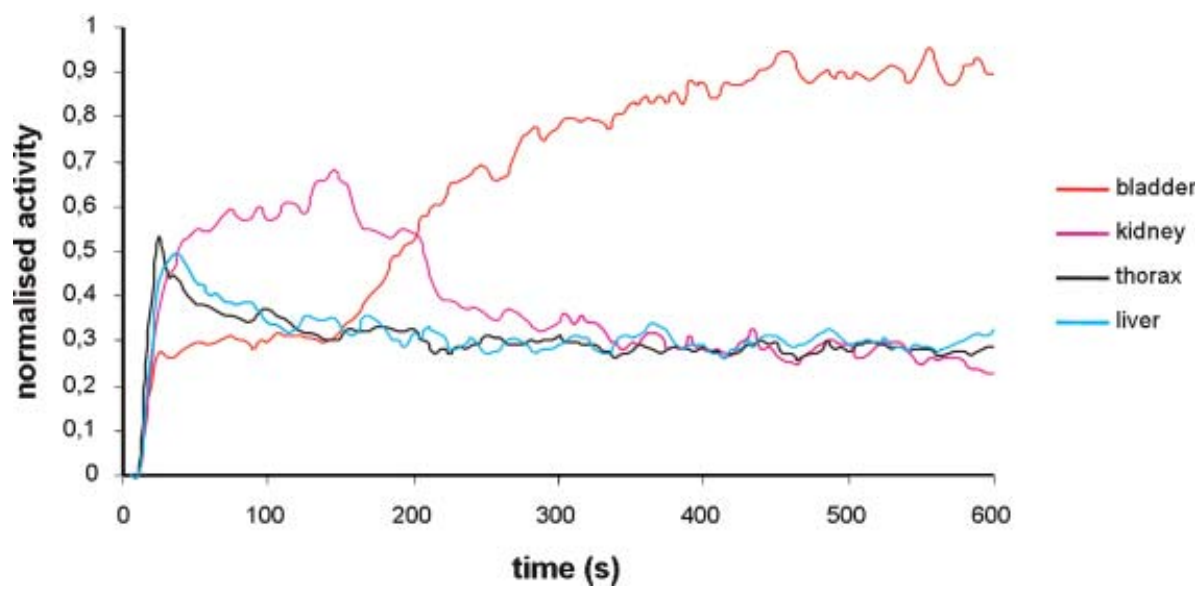

Figure 6. Time-activity curves obtained from dynamic scintigraphic images for the various regions of interest. The $y$-axis represents the normalized activity. This figure is available in colour online at www.interscience.wiley.com/journal/cmmi

(a)

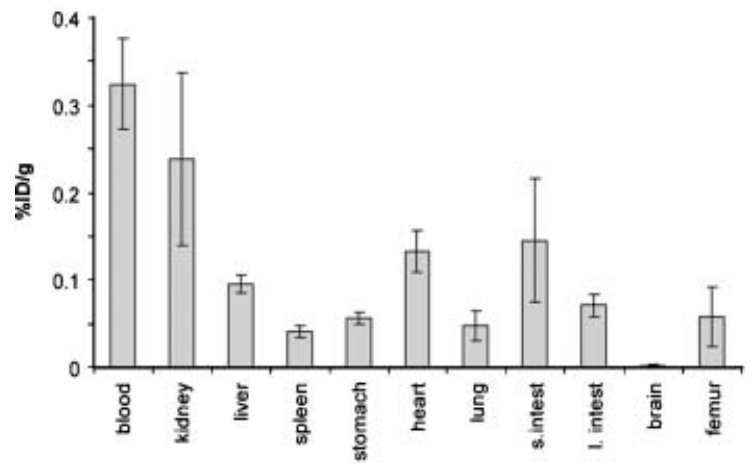

(b)

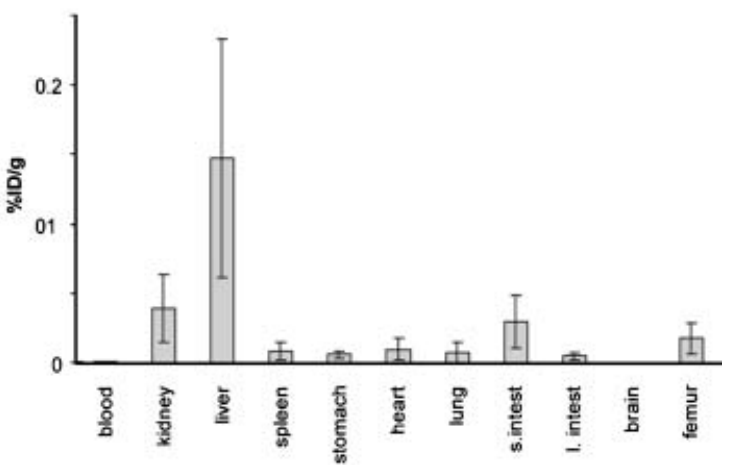

Figure 7. Biodistribution, stated as percentage of injected dose per gram of organ (\%ID/g \pm SD), of ${ }^{153} \mathrm{Sm}_{3} \mathrm{~L}$ in Wistar rats: (a) $15 \mathrm{~min}$ and (b) $1 \mathrm{~h}$ after intravenous injection. Results are the mean values of four animals.

are summarized in Fig. 7. At 15 min, the activity is overwhelmingly localized in the urine $\left(\% \mathrm{ID} \mathrm{g}^{-1}\right.$ in urine $\left.=10.0 \pm 5.12\right)$, which is in agreement with what was observed in the scintigraphic experiments. As expected, at $24 \mathrm{~h}$ after injection the activity dramatically decreased in all organs with the exception of the liver. The reason for such activity in the liver is still not clear. In the first instance it could probably be attributed to some later metal decomplexation; however if that was the case the activity value in the spleen and femur should also corroborate such an increase, which is not all observed.

\section{CONCLUSIONS}

Given its appropriate size and the corresponding rotational dynamics, $\mathrm{Gd}_{3} \mathrm{~L}$ has remarkable proton relaxivities at high magnetic field and is a prime candidate for CA applications in small animal MR imaging at high fields. MRI studies performed at 9.4 $\mathrm{T}$ in mice indicated that the in vivo $r_{1}$ relaxivity of $\mathrm{Gd}_{3} \mathrm{~L}$ is approximately three times higher than that of GdDOTA. The pharmacokinetics is similar for $\mathrm{Gd}_{3} \mathrm{~L}$ and GdDOTA, both following fast renal clearance in mice. Dynamic scintigraphic studies performed in rats using $\mathrm{Sm}_{3} \mathrm{~L}$ with ${ }^{153} \mathrm{Sm}$ enrichment are in accordance with this elimination pathway. The biodistribution results obtained at $15 \mathrm{~min}$ and $24 \mathrm{~h}$ post-injection gave further support to the scintigraphic and MRI results.

\section{EXPERIMENTAL}

153-Samarium chloride $\left({ }^{153} \mathrm{SmCl}_{3}\right)$ was produced at the ITN (Instituto Tecnológico e Nuclear), Lisbon, with a specific activity $>5 \mathrm{GBq} \mathrm{mg}^{-1}$. For this purpose a ${ }^{153} \mathrm{Sm}_{2} \mathrm{O}_{3}$ was prepared from a $98 \%$ samarium-152 enriched samarium oxide target, sealed into a quartz vial and welded into an aluminum can, by neutron irradiation using a thermal flux of $2.3 \times 10^{13} \mathrm{n} \mathrm{cm}^{-2} \mathrm{~s}^{-1}$. Following irradiation, the sample was opened, dissolved in $\mathrm{HCl}$ (1 $\mathrm{M}$ ) and the final 153-samarium chloride $\left({ }^{153} \mathrm{SmCl}_{3}\right)$ was brought to a stock concentration of $1.9 \mathrm{~mm}$.

\subsection{Sample preparation}

$\mathrm{A} \mathrm{GdCl}_{3}$ solution was prepared from $\mathrm{Gd}_{2} \mathrm{O}_{3}$ of $99.9 \%$ purity (Fluka) by dissolution in excess $\mathrm{HCl}$, which was evaporated off. The concentration of the metal ion was determined by complexometric titration with standardized $\mathrm{Na}_{2} \mathrm{H}_{2}$ EDTA solution. The synthesis of the ligand $\mathrm{H}_{12} \mathrm{~L}$ has been described previously (9). $G_{3} L$ was prepared by adding solid ligand to a solution of 
$\mathrm{GdCl}_{3}$ in 1:3 ligand to metal molar ratio. The $\mathrm{pH}$, measured with a calibrated combined glass electrode, was adjusted to 7.1 by addition of known amounts of $\mathrm{NaOH}(0.1 \mathrm{M})$. The absence of free metal was checked by the xylenol orange test.

$\mathrm{Sm}_{3} \mathrm{~L}$ was prepared by adding a ligand solution $(\mathrm{pH} 6.8)$ to a solution of $\mathrm{SmCl}_{3}$ (Sigma-Aldrich), where the concentration of the metal ion was determined by complexometric titration with standardized $\mathrm{Na}_{2} \mathrm{H}_{2}$ EDTA solution. A solution of ${ }^{153} \mathrm{SmCl}_{3}$ ( $\sim 74 \mathrm{MBq}$ ) was then added to the previous solution to reach 3:1 overall metal:ligand ratio.

\subsection{Animals}

MRI studies were performed in agreement with the French guidelines for animal care and in compliance with procedures approved by the appropriate institutional review committees. In vivo experiments were performed in male FVB/N mice (8-10 weeks, 24-26 g, obtained from Janvier Laboratories, Le GenestSt-Isle, France). All animals were kept in an animal housing facility, and given ad libitum access to food and water.

\subsection{CA injection}

$\mathrm{Gd}_{3} \mathrm{~L}(10 \mathrm{~mm})$ was injected in mice as a bolus via a tail vein catheter at a dose of $8 \mu \mathrm{mol} \mathrm{Gd} \mathrm{kg}{ }^{-1}$ body weight. For comparison, the experiments were repeated with injection of the small molecular weight contrast agent gadolinium(III)-1,4, 7,10 tetraazacyclododecane-1,4,7,10-tetraacetate ([Gd(DOTA) $(\mathrm{H} 2 \mathrm{O})]^{-}=$GdDOTA) (Dotarem, Guerbet, France).

The in vitro $r_{1}$ relaxivity at $9.4 \mathrm{~T}$ was approximately 3 times larger for $\mathrm{Gd}_{3} \mathrm{~L}$ than for GdDOTA (9). Thus, in the experiments where $T_{1}$ was measured, one group of mice received GdDOTA (30 mm) at a dose of $24 \mu \mathrm{mol} \mathrm{Gd} \mathrm{kg}{ }^{-1}$ BW (high dose). A lower dose ( $8 \mu \mathrm{mol} \mathrm{Gd} \mathrm{kg}{ }^{-1}$ BW, $10 \mathrm{~mm}$ ) of GdDOTA was also used in the DCE experiments for the sake of comparison.

\section{4. $M R$}

MRI experiments were carried out in a horizontal 9.4 T Bruker Biospec MR system (Bruker Biospin, Wissembourg, France) equipped with gradients capable of switching $950 \mathrm{mTm}^{-1}$ in $50 \mu \mathrm{s}$. A 12-element linear birdcage coil (Bruker Biospin) with inner diameter $35 \mathrm{~mm}$ and length $60 \mathrm{~mm}$ was used to achieve uniform excitation and reception.

A custom-built holder was used to fix the animals in the supine position into the birdcage coil. The mice were anesthetized with isoflurane (1.5-2.5\%) in an $\mathrm{O}_{2}-\mathrm{N}_{2} \mathrm{O}$ 1:1 mixture applied with a face mask allowing free breathing. Respiration was monitored using a balloon taped to the thorax and connected to a pressure transducer (SA Instruments, Inc., Stony Brook, NY, USA). The mice body temperature was monitored with a rectal thermo-sensor and kept at $37 \pm 0.5^{\circ} \mathrm{C}$ throughout the experiment, using a plastic tube with circulating warm water positioned around their bodies.

\subsubsection{DCE experiments}

Regional contrast agent uptake was assessed using dynamic contrast enhanced (DCE) MRI. DCE experiments were carried out using a series of 100 inversion-recovery TrueFISP coronal images ( $1.5 \mathrm{~mm}$ thick) of mouse kidneys with an inversion delay of $1.5 \mathrm{~s}$. This inversion time value corresponds to the 'nulling point' for the medulla kidney ( $T_{1}$ renal medulla $>T_{1}$ renal cortex). After adiabatic inversion one image was acquired with the following parameters: $T R / T E=2 / 1 \mathrm{~ms}$, at $250 \mathrm{kHz}$ readout bandwidth, $0.95 \mathrm{~ms}$ hermite $60^{\circ}$ excitation pulse, field-of-view $(\mathrm{FOV})=$ $50 \times 23 \mathrm{~mm}$, matrix $=128 \times 96$. The acquisition time for this image was $291.2 \mathrm{~ms}$. Temporal resolution (i.e. time period between the start of two successive images) was $20 \mathrm{~s}$ before CA injection and $6 \mathrm{~s}$ thereafter. The overall experimental duration was $12 \mathrm{~min}$.

\subsubsection{In vivo $T_{1}$ time course measurements}

$T_{1}$ measurements were performed using a series of continuous inversion recovery TrueFISP (24) images with the following parameters: $T E=1 \mathrm{~ms}, T R=2 \mathrm{~ms}$, flip angle $=60^{\circ}$, number of $T_{1}$ blocks $=80$, range of inversion time $(T I)=63.6-5158.9 \mathrm{~ms}, \mathrm{TI}$ increment (i.e. acquisition time for one frame) $=145.58 \mathrm{~ms}$, number of frames $=36$. Bolus injection of the contrast agents, flushed with $\sim 200 \mu$ l of saline, was carried out immediately after the sixth IR block. A delay was introduced between the start of two successive blocks to allow for longitudinal relaxation before the next inversion. The temporal resolution (i.e. time period between the start of two successive blocks, or $T R_{\text {block }}$ ) was $20 \mathrm{~s}$ before CA injection and $8 \mathrm{~s}$ thereafter; $F O V=50 \mathrm{~mm} \times 23 \mathrm{~mm}$, matrix $=64 \times 48,1$ coronal slice, slice thickness $=1.5 \mathrm{~mm}$. The overall experimental duration was $12 \mathrm{~min}$.

\subsection{MRI data processing}

\subsection{1. $\quad T_{1}$ mapping}

Image analysis and processing were performed with the public domain software ImageJ ( $\mathrm{NIH}$, http://rsb.info.nih.gov/ij) and MATLAB (Mathworks Inc., Natick, MA, USA). $T_{1}$ maps were performed for each time point on a pixel-by-pixel basis from each image using the following model function (24):

$$
S(t)=S_{\text {stst }}\left[1-I N V \cdot \exp \left(-t / T_{1}{ }^{*}\right)\right]
$$

where $S(t)$ is the signal time course (following an inversion pulse) and $S_{\text {stst }}$ denotes the steady state signal for large inversion times $t$. INV, the inversion factor, is also dependent on relaxation times and is related to the relation between the initial inverted magnetization and the steady-state signal (24). The apparent spin-lattice relaxation time $T_{1}{ }^{*}$ describes the dynamic of the signal recovery to $S_{\text {stst }}$. If off-resonance effects may be neglected, the following formula relates the fitting parameters of eqn (1) to the longitudinal relaxation time (24):

$$
T_{1}=T_{1}{ }^{*} \cos (\theta / 2)(I N V-1),
$$

where $\theta$ is the excitation angle.

Regions of interest (ROIs) corresponding to the kidney cortex and medulla, and vascular system, were first drawn on anatomical images and then copy-pasted in the $T_{1}$ maps. The time course of the relaxivity rates $\left(\Delta R_{1} \equiv R_{1}-R_{10}=1 / T_{1}-1 / T_{10}\right)$ was calculated for these ROls ( $T_{10}$ and $T_{1}$ are the spin-lattice relaxation values pre- and post-contrast agent injection, respectively).

\subsection{Biodistribution and dynamic scintigraphic studies}

A $\gamma$ camera-computer system (GE 400 GenieAcq, from General Electric, Milwaukee, USA) was used for acquisition and pre-processing. Data processing and display were performed on a personal computer using software developed for the IDL 5.2 computer tool. A well counter (DPC-Gamma C12, LA, USA) with a 
Compaq DeskPro compatible computer was used for activity counting in the biodistribution studies.

Gamma images were obtained and biological distribution of the ${ }^{153} \mathrm{Sm}_{3} \mathrm{~L}$ complex was determined using $200 \mathrm{~g}$ Wistar rats. All animal studies were carried out in compliance with procedures approved by the appropriate institutional review committees. Conscious rats were allowed free access to food and water. Four animals were anaesthetized with ketamine $\left(50 \mathrm{mg} \mathrm{ml}^{-1}\right)$ chloropromazine (2.5\%) (10:3) and injected in the femoral vein with $\sim 200 \mu \mathrm{Ci}$ of $\mathrm{Sm}^{*}{ }_{3} \mathrm{~L}$. The animals were then positioned in dorsal decubitus over the detector. Image acquisition was initiated immediately before radiotracer injection. Sequences of 120 images (of $5 \mathrm{~s}$ each), were acquired to $64 \times 64$ matrices. Images were subsequently processed using an IDL based program (Interactive Data Language, Research Systems, Boulder, CO, USA).

In order to analyze the transport of the radiotracer over time, four regions of interest (ROI) were drawn on the image files, corresponding to the thorax, liver, left kidney and bladder. The time-activity curves were obtained from these regions. Animals were sacrificed $15 \mathrm{~min}$ after injection and the majors organs removed were weighted and counted in a $\gamma$ well-counter. Similar biodistribution studies with a group of four rats sacrificed $24 \mathrm{~h}$ after intravenous injection of ${ }^{153} \mathrm{Sm}_{3} \mathrm{~L}$ were also performed.

\section{Acknowledgements}

This work was financially supported by the Centre National pour la Recherche Scientifique (CNRS, France), the Swiss National Science Foundation, the Swiss State Secretariat for Education and Research (SER), the Foundation of Science and Technology (FCT), Portugal (project POCTI/QUI/47005/2002) and FEDER. It was carried out in the frame of the EC COST Action D38 and the European-founded EMIL programme (LSCH-2004-503569). P.L.S. gratefully acknowledges Le Studium (Agency for research and international hosting associate researchers in 'Region Centre'), Orleans, France for financial support. The authors wish to thank Dr Maria dos Anjos Neves, at the ITN (Instituto Tecnológico e Nuclear), Lisbon, for providing the 153-Samarium chloride $\left({ }^{153} \mathrm{SmCl}_{3}\right)$.

\section{REFERENCES}

1. Pautler RG. Mouse MRI: Concepts and Applications in Physiology. Physiology 2004; 19: 168-175.

2. Caravan P, Ellison JJ, McMurry TJ, Lauffer RB. Gadolinium(III) chelates as MRI contrast agents: structure, dynamics, and applications. Chem. Rev. 1999; 99: 2293-2352.

3. Merbach $\mathrm{AE}$, Tóth É (eds). The Chemistry of Contrast Agents in Medical Magnetic Resonance Imaging. Wiley: Chichester, 2001.

4. Caravan P. Strategies for increasing the sensitivity of gadolinium based MRI contrast agents. Chem. Soc. Rev. 2006; 35: 512.

5. Tóth E, Helm L, Merbach AE. Relaxivity of gadolinium(III) complexes: theory and mechanism. In The Chemistry of Contrast Agents in Medical Magnetic Resonance Imaging, Merbach $A E$, Tóth É (eds). Wiley: Chichester, 2001; 45-120.
6. Livramento JB, Tóth E, Sour A, Borel A, Merbach AE, Ruloff R. High relaxivity confined to a small molecular space: a metallostarbased, potential MRI contrast agent. Angew. Chem. Int. Edn 2005; 44: 1504-1508.

7. Livramento JB, Sour A, Borel A, Merbach AE, Tóth E. Six Gd ${ }^{3+}$ ions densely packed in a starburst-shaped heterometallic compound. Chem. Eur. J. 2006; 12: 989-1003.

8. Livramento JB, Weidensteiner C, Prata MIM, Allegrini PR, Geraldes CFGC, Helm L, Kneuer R, Merbach AE, Santos AC, Schmidt P, Tóth É. First in vivo MRI assessment of a self-assembled metallostar compound endowed with a remarkable high field relaxivity. Contrast Media Mol. Imag. 2006; 1: 30-40.

9. Livramento JB, Helm L, Sour A, O'Neil C, Merbach AE, Tóth E. A benzene-core trinuclear $\mathrm{Gd}^{\prime \prime \prime}$ complex: towards the optimization of relaxivity for MRI contrast agent applications at high magnetic field. Dalton Trans. 2008; 1195.

10. Brücher E, Sherry AD. Stability and toxicity of contrast agents. In The Chemistry of Contrast Agents in Medical Magnetic Resonance Imaging, Tóth E, Merbach AE (eds). Wiley: Chichester, 2001; 243.

11. Costa J, Tóth É, Helm L, Merbach AE. Dinuclear, bishydrated Gd ${ }^{\prime \prime \prime}$ polyaminocarboxylates with a rigid xylene core display remarkable proton relaxivities. Inorg. Chem. 2005; 44: 4747-4755.

12. Paul-Roth C, Raymond KN. Amide functional group contribution to the stability of gadolinium(III) complexes: DTPA derivatives. Inorg. Chem. 1995; 34: 1408-1412.

13. Tweedle MF, Eaton SM, Eckelman WC, Gaughan GT, Hagan JJ, Wedeking PW, Yost FJ. Comparative chemical structure and pharmacokinetics of mri contrast agents. Invest. Radiol. 1988; 23(suppl. 1): S236-S239.

14. Harpur ES, Worah D, Hals PA, Holtz E, Furuhama K, Nomura H. Preclinical safety assessment and pharmacokinetics of gadodiamide injection, a new magnetic resonance imaging contrast agent. Invest. Radiol. 1993; 28(suppl. 1): S28-S43.

15. Baumann D, Rudin M. Quantitative assessment of rat kidney function by measuring the clearance of the contrast agent Gd(DOTA) using dynamic MRI. Magn. Res. Imag. 2000; 18: 587-595.

16. Pickup $S$, Wood AKW, Kundel HL. Gadodiamode $T_{1}$ relaxivity in the brain tissue in vivo is lower than in saline. Magn. Reson. Med. 2005; 53: 35-40.

17. Raghunand N, Howison C, Sherry AD, Zhang S, Gillies RJ. Renal and systemic $\mathrm{pH}$-imaging by contrast-enhanced MRI. Magn. Reson. Med. 2003; 49: 249-257.

18. Shuter B, Tofts PS, Wang SC, Pope JM. The relaxivity of Gd-EOB-DTPA and Gd-DTPA in liver and kidney of the Wistar rat. Magn. Reson. Imag. 1996; 14: 243-253.

19. Pedersen M, Morkenborg J, Jensen FT, Stodkilde-Jorgensen $H$, Djurhuus JC, Frokieer J. In vivo measurements of relaxivities in the rat kidney cortex. Magn. Reson. Imag. 2000; 12: 289-296.

20. Gillis A, Gray M, Burstein D. Relaxivity and diffusion of gadolinium agents in cartilage. Magn. Reson. Med. 2002; 48: 1068-1071.

21. Aime S, Botta M, Bruce Jl, Mainero V, Parker D, Terreno E. Modulation of the water exchange rates in [Gd-DO3A] complex by formation of ternary complexes with carboxylate ligands. Chem. Commun. 2001; 115-116.

22. Prata MIM, Santos AC, Neves M, Geraldes CFGC, Lima JJP. ${ }^{153} \mathrm{Sm}^{3+}$ and ${ }^{111} \ln ^{3+}$ DTPA derivatives with high hepatic specificity: in vivo and in vitro studies. J. Inorg. Biochem. 2002; 91: 312-319.

23. Alves FC, Donato P, Sherry AD, Zaheer A, Zhang S, Lubag AJM, Merritt ME, Lenkinski RE, Frangioni JV, Neves M, Prata MI, Santos AC, de Lima JJ, Geraldes CF. Silencing of phosphonategadolinium magnetic resonance imaging contrast by hydroxyapatite binding. Invest. Radiol. 2003; 38(12): 750-760.

24. Schmitt P, Griswold MA, Jakob PM, Kotas M, Gulani V, Flentje M, Haase A. Inversion recovery TrueFISP: quantification of $T_{1}, T_{2}$, and spin density. Magn. Reson. Med. 2004; 51: 661-667. [Erratum in: Magn. Reson. Med. 2004; 52: 698]. 